\title{
Geomagnetic Observations at the Sagami Trough by Use of a New Type of Three-Component Ocean Bottom Magnetometer
}

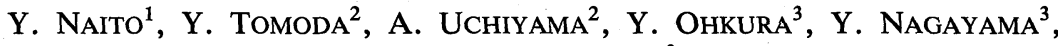 \\ and $\mathrm{Y}$. TAKAHASHI ${ }^{3}$ \\ ${ }^{1}$ Department of Earth Sciences, Faculty of Sciences, Chiba University, Japan \\ ${ }^{2}$ Ocean Research Institute, University of Tokyo, Japan \\ ${ }^{3}$ Process Instrumentation Division, Shimadzu Corporation, Japan
}

(Received June 22, 1983; Revised April 5, 1984)

\begin{abstract}
A new type of ocean bottom magnetometer (OBM) for investigations of conductivity anomaly (CA) was built according to the philosophy of design that it should be small in size, light in weight, easy to operate, strong enough against mechanical shocks, capable of long-term observations with an accuracy better than $1 \mathrm{nT}$. The device of the pop-up type OBM has several characteristics as follows; small fluxgate sensors are used for magnetic detection, outputs of sensors are converted to digital data and stored in magnetic bubble memories, electric power is supplied intermittently for economy's sake; the measurement system is installed in a pressure-tight glass sphere with an outer diameter of about 43 $\mathrm{cm}$, and its recovery from the ocean bottom is made by sending an ultrasonic command from a ship to the releasing system of the OBM.

After a successful test on land, trial observations were carried out in the Sagami Trough at the water depth of about $1,500 \mathrm{~m}$. Records were obtained for the whole period of observation from November 13 to December 16, 1982, and analyzed to give transfer functions and Parkinson vectors. The results seem to be consistent with the central Japan anomaly for geomagnetic variation with a period longer than ten odd minutes. For the period of ten minutes, other type of conductivity anomaly seems to exist.
\end{abstract}

\section{Introduction}

Anomalous behaviors of geomagnetic variations of the short period have been studied over decades in Japan by RIKITAKE et al. (1952) and others, and those anomalous variations are interpreted by lateral inhomogeneities of electrical conductivity distribution, so called CA (conductivity anomaly), such as the central Japan anomaly (RIKITAKE, 1959) or northeastern Japan anomaly (KATO et al., 1971). It is important to observe the geomagnetic variations at the sea-floor from a viewpoint of CA investigation in a region surrounded by the sea like Japan. Nevertheless very few observations have been carried out at the sea-floor around Japan because of the lack of and delay in developing 
necessary instruments to do this specific work.

The first geomagnetic observation on the sea-floor was made by FILLoux (1967), and since then, Filloux (1977 and 1978) has carried out ocean bottom electromagnetic measurements in the northeastern Pacific Ocean and the northern central Pacific Ocean using suspended-magnet type magnetometers and electric field recorders. He employed the magneto-telluric method that is often used on land for deducing the electrical conductivity structure at a depth from correlation of electric to magnetic fields near the surface.

Recently, a fluxgate-type ocean bottom magnetometer has been developed by SEgAwA et al. (1981) or TOMODA et al. (1981), and practical observations were carried out off the San-Riku coast and in the northern Japan Sea by SEGAWA et al. (1982) using three-component magnetometers.

The authors have solved various problems encountered through development of a pop-up type three-component ocean bottom magnetometer for the purpose of investigations of CA.

In this paper, some characteristics of a new type magnetometer are described, and the reliability of the device is estimated from various tests. Actual observations were made at the sea-floor by use of the new device and their results are reported.

\section{Preliminary Study for an Ocean Bottom Magnetometer}

A study for the development of an ocean bottom magnetometer (OBM) was started in 1980 using fluxgate sensors for magnetic detection (TOMODA et al., 1981). In the first year, a single-component magnetometer (see Fig. 1) was built as a trial device in order to examine feasibility of the geomagnetic measurement at the sea-floor. Resultant informations as follows were obtained by the device.

\subsection{Method of cancelling the main geomagnetic field}

It is necessary to cancel the main geomagnetic field in order to get a wide

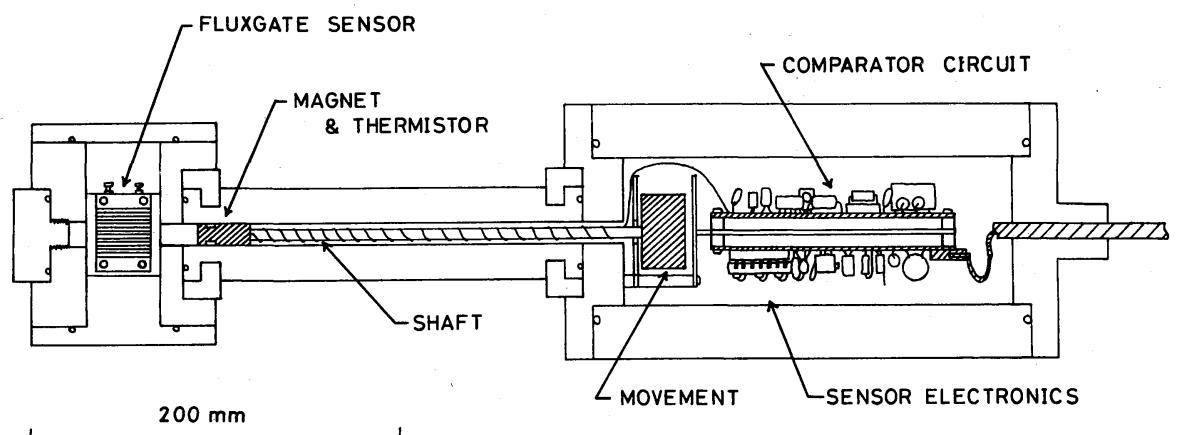

Fig. 1. Trial model of single component magnetometer constructed in 1981 . 
dynamic range for measurement. A method cancelling the main field by rotating a permanent magnet was tried for the trial device to save power consumption. Although this method is simple, the correction for the temperature effect on the permanent magnet is another serious problem. And so the main geomagnetic field is cancelled by digitally controlled constant currents for the new type of ocean bottom magnetometer as will be mentioned later.

\subsection{Temperature effect}

Characteristics of three sets of Schonstedt's fluxgate sensors were studied for the trial device. The fluxgate sensors have large temperature coefficients. Moreover, the coefficient is different for each sensor and varies with the magnitude of the sensor output, i.e., the intensity of measuring field. In order to remove these temperature effects, temperature data as well as geomagnetic data were recorded and it was tried to correct the temperature effects in the off-line data processing by use of an electronic computer. It was quite difficult to obtain an accuracy of $1 \mathrm{nT}$ by this method.

Shimadzu's fluxgate sensors with quite small temperature coefficients are used for the new type of OBM. Temperature data are also recorded with a resolution of 0.01 degree by way of precaution.

\subsection{Economy of power consumption}

Intermittent power supply was necessary for the sake of power economy, and this process does not prevent a measurement if delay time of sampling is taken adequately long, i.e., more than $500 \mathrm{msec}$, after power is on. This method adopted for the trial device is used as it is in the new OBM model.

In 1981, studies for the application of the magnetic bubble memory to a data recording system were made (UCHIYAMA et al., 1982), and it was confirmed that the bubble memory worked well in intermittent operation which was the most significant problem for the OBM. Details of the magnetic bubble memory and its significance will be described later.

\section{Characteristics of the New Type of Ocean Bottom Magnetomer}

A new type of ocean bottom magnetometer was built in the summer of 1982, according to the following philosophy of design of the device, that is, the device for measurement of conductivity anomaly at the sea-floor should be

1) small in size and light in weight,

2) easy to operate especially in deploying and in retrieving,

3) strong enough against mechanical shocks,

4) capable of long-term observations (longer than 3 months), and

5) accurate to more than $1 \mathrm{nT}$ (nanno-Tesla).

The main body of the magnetometer is composed of two parts, i.e., a system 
for measurement and a system for self-surfacing. The measurement system consists of a sensor unit, a sensor electronics unit, an electronics unit for A/D conversion of the sensor output and D/A conversion for the constant magnetic field compensation, a data control unit, and a power supply unit. The self-surfacing system consists of two pieces of hard-hats, an ultrasonic transponder and a transducer, a stand, a release mechanism, floating units, and a flash light.

\subsection{Fluxgate sensors and their accuracy}

Three fluxgate sensors used for magnetic detection, produced by Shimadzu Corporation, are assembled perpendicular to each other in order to avoid mutual interference (see Fig. 2). The space occupied by the sensor unit is at most a cube with a length of $5.4 \mathrm{~cm}$ on each side.

In this measurement system, there is a significant difference from the trial device described in Section 2 in the method of cancelling the main geomagnetic field. That is, the constant current compensation method digitally controlled by micro-processor is adopted instead of the rotating of a permanent magnet. Accuracy of at least $1 \mathrm{nT}$ is assured by the present method.

Figure 3 shows the comparison of analogue records of $Z$ (vertical) component of the fluxgate magnetometer with a SQUID (Superconducting Quantum Interference Device) magnetometer made by Shimadzu Corporation in simultaneous sensitive measurement carried out at Kakioka in April, 1982. As seen in the figure, the fluxgate has sufficient accuracy when compared with the reliable SQUID, although high frequency noises are seen on both records. It is found from the records of higher chart speed that the noises in SQUID magnetometer predominant in $Z$ component are regular with an amplitude of $0.05 \mathrm{nT}$ and the period of the noise is exactly 1 second. And it was concluded that these noises were caused by the earth current of the counter of a telephone relay station.

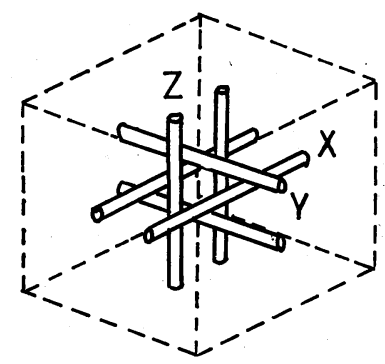

\section{SENSOR UNIT}

Fig. 2. Assembly of fluxgate sensors. Length of each side of cube, indicated by dotted line, is $5.4 \mathrm{~cm}$. 


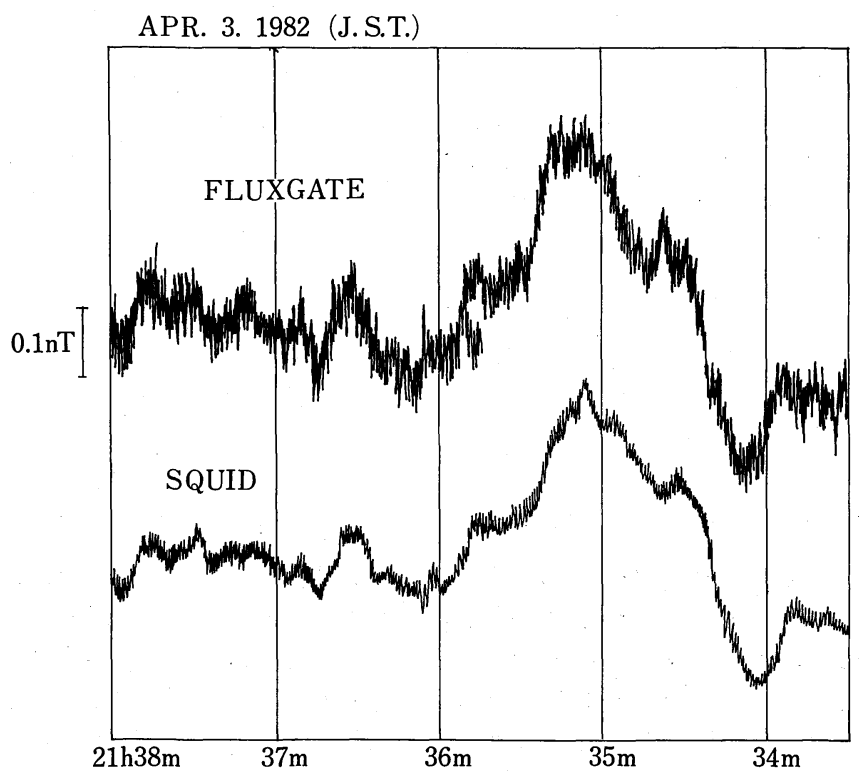

Fig. 3. Comparison of the analogue record of fluxgate $Z$ component with that of the SQUID magnetometer.

\subsection{Data processing and recording system}

Measured analogue geomagentic data are digitally converted by 13 bits A/D converter and the difference of successive data is recorded as 8 bits digital data in RAM (Random Access Memory). The possible range of measuring the geomagnetic field is $\pm 400 \mathrm{nT}$ with a resolution of $0.1 \mathrm{nT}$. Data in the RAM are transferred to the magnetic bubble memory every 24 hours.

One of the features of the new type magnetometer is the magnetic bubble memory recording system (UCHIYAMA et al., 1982), which is a kind of non-volatile recording medium with a high recording density. Table 1 shows the comparison of some characteristics with CMOS RAM and the cassette magnetic tape. Although the power consumption is pretty large compared with CMOS RAM, the magnetic bubble memory is suitable for a recording system used at the ocean bottom because of its reliability and intermittent operation (1.9 sec every 8 hours). One bubble memory cassette has 32 kilo-bytes memory size. As the magnetometer has five cassettes, total capacity is 160 kilo-bytes, which correspond to records of over 90 days at 2.5 minutes' sampling interval.

\subsection{Power consumption and property of battery discharge}

Batteries for the measurement operation are lithium dry cells, and the elec- 
Table 1. Comparison of magnetic bubble memories with CMOS RAM and cassette magnetic tapes.

\begin{tabular}{|c|c|c|c|}
\hline Parameter & Bubble memory & COMS RAM & $\begin{array}{c}\text { Cassette tape } \\
\text { (MT-2) }\end{array}$ \\
\hline Capacity & 160 kbytes & 160 kbytes & 256 kbytes \\
\hline The number of memory & 5 & 80 & 1 \\
\hline Dimension & $200 \times 50 \mathrm{~mm}$ & $280 \times 200 \mathrm{~mm}$ & $100 \times 65 \mathrm{~mm}$ \\
\hline Power & $7.2 \mathrm{~W}$ & $20 \mu \mathrm{W} \times 80=1.6 \mathrm{~mW}$ & $15 \mathrm{~W}$ \\
\hline Access & Random/sequential & Random/sequential & Sequential \\
\hline Data rate & $86 \mathrm{kbits} / \mathrm{sec}$ & $2.5 \mathrm{Mbits} / \mathrm{sec}$ & $12 \mathrm{kbits} / \mathrm{sec}$ \\
\hline Mechanical shock & 0 & 0 & $x$ \\
\hline Static electricity & 0 & $x$ & 0 \\
\hline
\end{tabular}

tric power is supplied intermittently only at the time of sampling for the sake of saving power consumption which enables long-term observasion at the seafloor. There is, however, a serious problem for lithium dry cells in case of low temperature operation. Figure 4 shows pulse discharge characteristics of a brandnew lithium dry cell with the capacity of 15 Ah (Ampere-hour). Three seconds discharging was repeated every 15 seconds. No adequate voltage was obtained until 5 minutes after discharging started with $6 \Omega$ load. Because it was assured

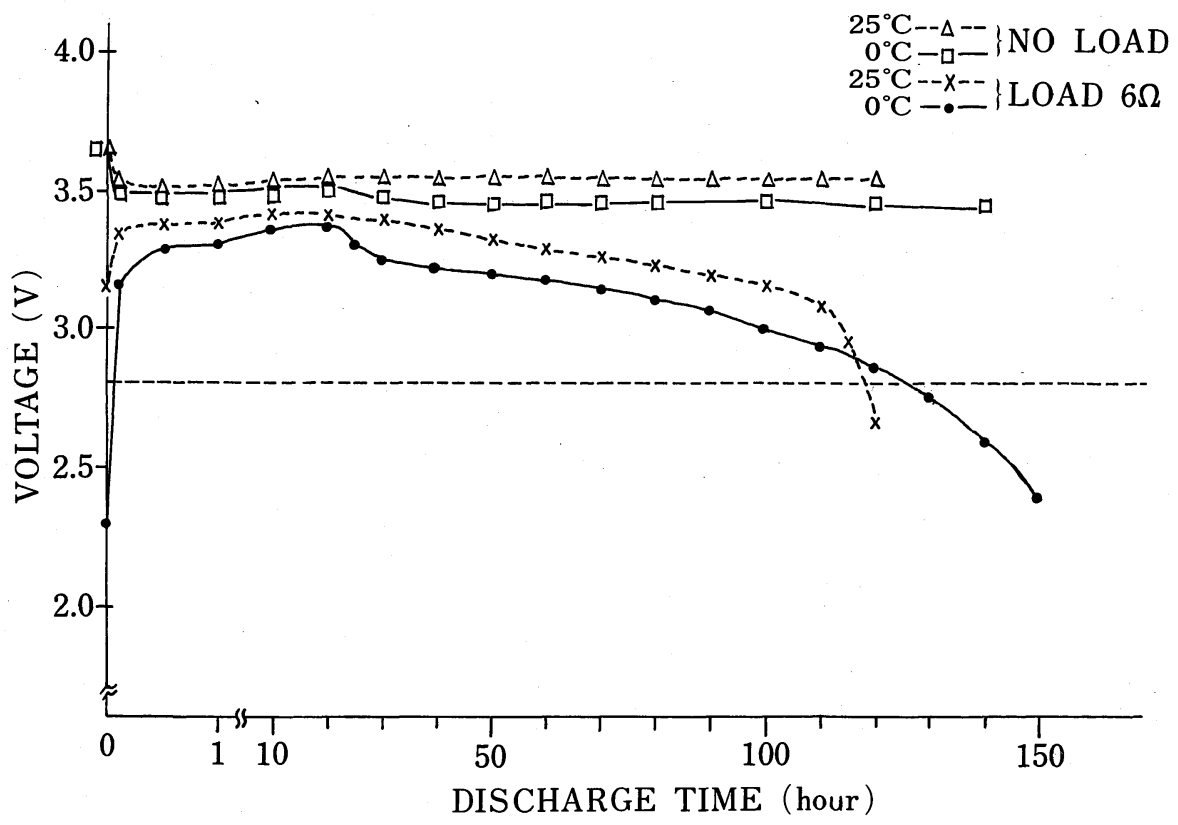

Fig. 4. Pulse discharge characteristic curve of lithium dry cell with large capacity of $15 \mathrm{Ah}$. Three seconds discharging was repeated every 15 seconds. The lithium dry cell can supply enough power at $0^{\circ} \mathrm{C}$ after discharging for more than 1 minute. First 1 hour is exaggerated in time. 
that discharging characteristics shown in the figure did not change when the interval of discharging was elongated, it takes about 1 hours to read an adequate voltage, higher than 2.5 volts, in case of actual operation at the sampling interval of 2.5 minutes. This feature of discharging is more serious in the lithium dry cell of a smaller capacity of 5.5 Ah used in earlier experiments at sea and caused failures as will be mentioned later. The problem can be solved by discharging the cell before its use to attain the necessary voltage, which is particular characteristics of a lithium battery.

\subsection{Levelling mechanism and installation arrangement}

The measurement system is installed in a pressure-tight glass spherical capsule with an outer diameter of $43 \mathrm{~cm}$, and can rotate in the capsule by means of three tephron-coated ball bearings put in the balance weight at the bottom of the assembly of measurement system (see Fig. 5). Therefore, even if the magnetometer is inclined, the sensors fixed at the center of the system in the capsule return to the vertical position within an accuracy of about 0.5 degree.

Electronic circuit boards and battery packs are symmetrically laid on the

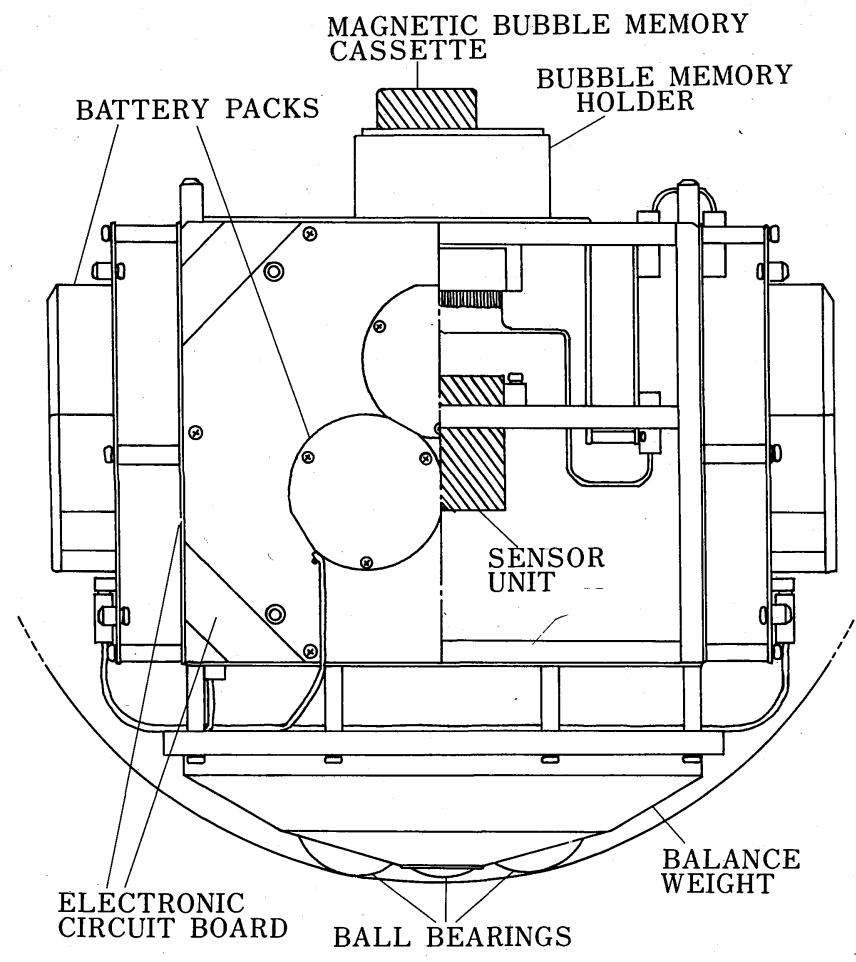

Fig. 5. Assembly of the measurement system. Sensor unit is fixed at the center of the system. This assembly is installed in a pressure-tight glass sphere. 
cubic flame around the sensor unit to compensate for the magnetic effect of each electronic device. Bubble memory cassettes are installed in the holder at the top of the flame. An ultrasonic transducer, a releasing device, buoyant materials and a flash light are fixed around and at the top of the upper hard-hat. At the bottom of the lower hard-hat, an ultrasonic transponder is fixed.

The above-mentioned instruments, including a recovery unit, are fixed to a stand by two bands through hooks of the release mechanism at the top of the upper hard-hat. The stand holds some lead sheet ballast and remains on the sea-floor after the release operation.

Overall appearance of the magnetometer is shown in Fig. 6. The total weight in air is about $160 \mathrm{~kg}$, including the ballast, and the weight of the recovery unit itself is approximately $110 \mathrm{~kg}$.

\section{Test on Land}

The instrument was tested on land at the field station of the Kakioka Geophysical Research Laboratory, Faculty of Science, University of Tokyo, in Ibaraki Prefecture, which is about $0.5 \mathrm{~km}$ from the Kakioka Geomagnetic Observatory of the Japan Meteorological Agency.

The magnetometer in a glass capsule and hard-hats was buried at about one meter underground, and geomagnetic variations were measured at 2.5 minutes' sampling interval for about five days. Figure 7 shows a part of the record obtained. $X$ and $Y$ indicate horizontal components of geomagnetic variations in perpendicular directions, and $Z$ is the vertical. The records of $Z$ component are compared with the records of the KASMMER (Kakioka Standard Magnetometer) in the Kakioka Geomagnetic Observatory in order to examine the reliability of the device. A part of both records and the difference between the two are shown in Fig. 8, in which vertical lines indicate the Japan Standard Time.

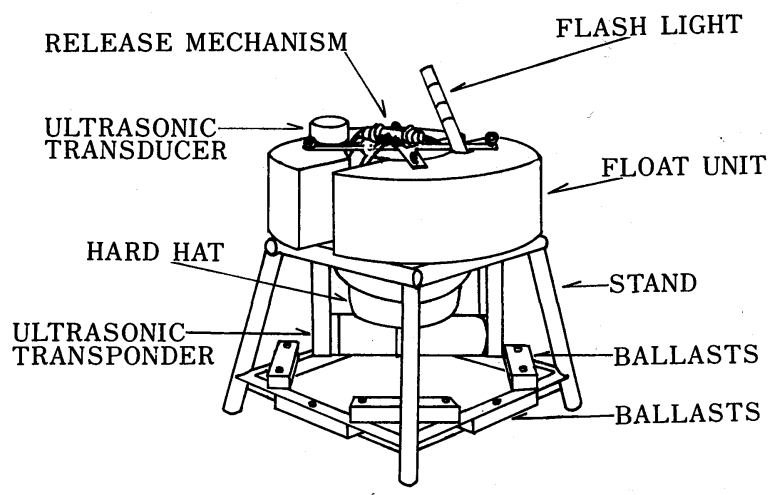

Fig. 6. Overall appearance of the magnetometer. Total weight in air is about $160 \mathrm{~kg}$. 


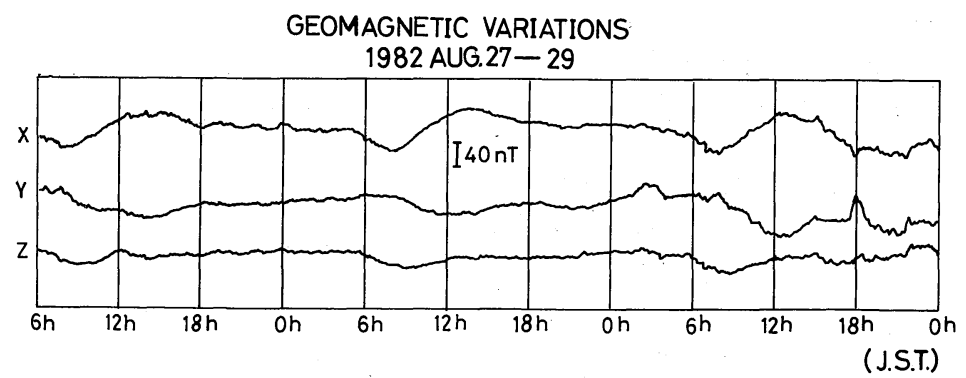

Fig. 7. A part of the records of geomagnetic variations obtained during the measurement test at Kakioka. $X$ and $Y$ indicate horizontal components and $Z$ the vertical. Vertical lines indicate the Japan Standard Time, of which the interval is 2 hours.

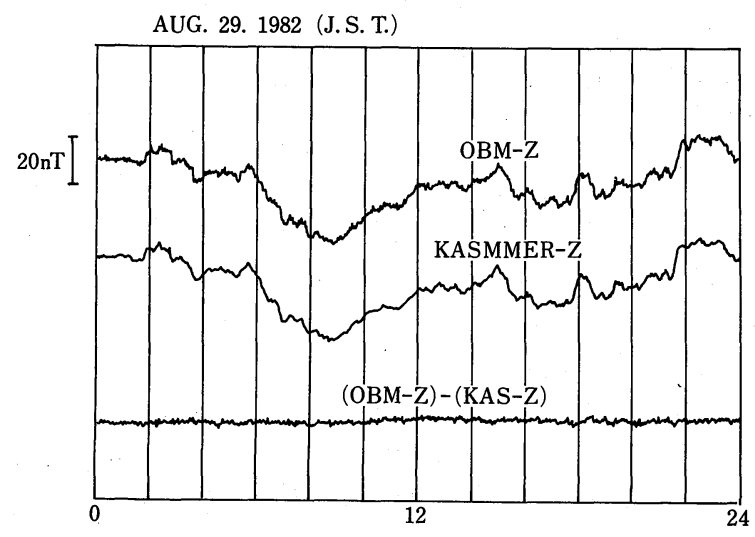

Fig. 8. Comparison of $Z$ component of geomagnetic variations obtained by the new type of magnetometer (OBM-Z) with the Kakioka Standard Magnetometer (KASMMER-Z). Lowermost zig-zag line with notation of '(OBM-Z)-(KAS-Z)' indicates the difference of the two.

\section{Pop-Up Test and Trial Observation at Sea}

The self-surfacing system was tested in the water tank of the JAMSTEC (Japan Marine Science and Technology Center) in Aügust, 1982. It was confirmed that the magnetometer went down stably in water without inclination and came up under the same conditions after release from the stand. This behavior was observed through several windows around the tank.

In September, the magnetometer was set on the sea bottom at a depth of 3800 meters off Omae-Saki. It was ascertained by this test, that the self-surfacing system was operated under high water pressure and that theoretically calculated speeds of free-fall and pop-up, $1.0 \mathrm{~m} / \mathrm{sec}$ and $0.8 \mathrm{~m} / \mathrm{sec}$, respectively, were reasonable. No magnetic record was obtained, because, as was clarified later, a lithium dry cell of a low electric capacity of 5.5 Ah, does not supply adequate power at low temperature until it has been discharged for more than 5 minutes. 
The second trial observation was carried out at the site of $34^{\circ} 59.1^{\prime} \mathrm{N}$, $139^{\circ} 19.8^{\prime} \mathrm{E}$, in the Sagami Bay, the location of which is demonstrated in Fig. 9, by R/V Tansei-Maru of the Ocean Research Institute, University of Tokyo, from November 5 to 13,1982 . These test records were obtained for only 11 hours after reaching the ocean bottom due to a battery failure which was the same as experiences in the previous test, that is, the electric power supply went down below a certain threshold level due to low temperature so that the bubble memory could not work further to protect the data in the memory.

Immediately after the second trial, a third test was carried out at the same site using another magnetometer from November 13 to December 16. In this test, lithium batteries were used after they had been discharged on land to reach the required voltage, and the threshold level for the bubble memory was set lower than before.

At the time of recovery and installation on November 13, speed of the device while floating up and falling down were 'watched' by measuring the slant range from the ship to the magnetometer. The results are shown in Figs. 10(a) and (b). It is well indicated that speeds of pop-up and free-fall are constant.

Geomagnetic records were successfully obtained for all the periods of observation. Figure 11 shows the records of magnetic fields $(X, Y, Z)$ and temperature at the time of launching the magnetometer, covering the period from beforelaunching, when the magnetometer was on board a ship, to after-installation on the sea-floor. The stability of the device at the time of launching and while descending in the water are well demonstrated by three curves. The records about 4 days after reaching the sea floor are shown in Fig. 12. Many spikes seen on the temperature curve are regarded as fluctuations of the least significance, of the A/D converter, with a magnitude of $0.01^{\circ} \mathrm{C}$.

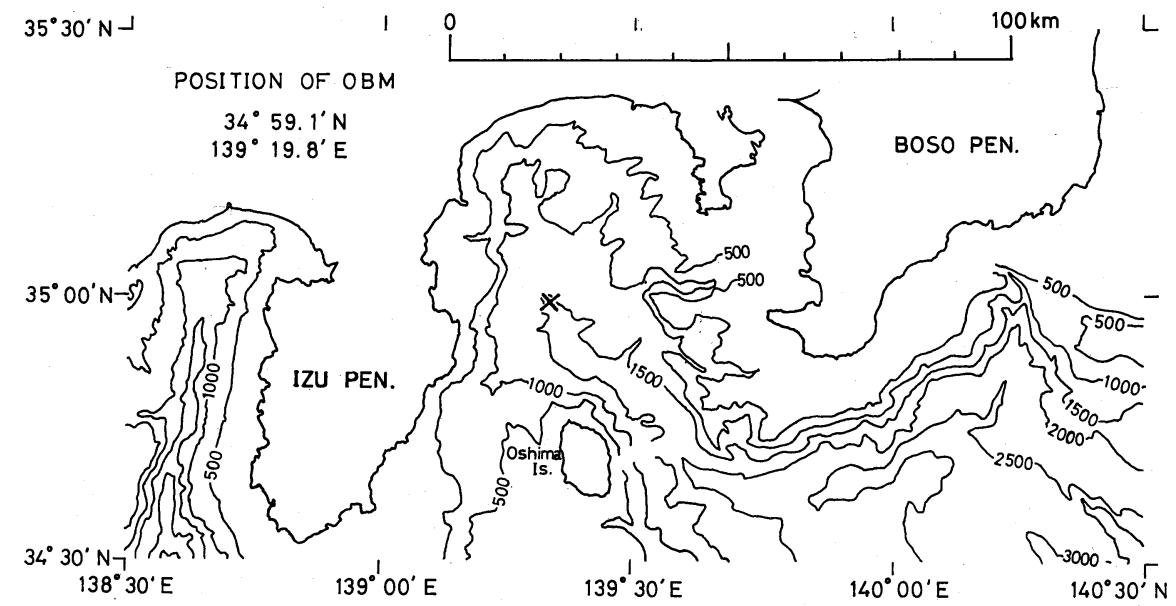

Fig. 9. Trial observation was carried out three times in the Sagami Trough, and the location is demonstrated by a cross. Bathymetric contours are given every 500 meters. 

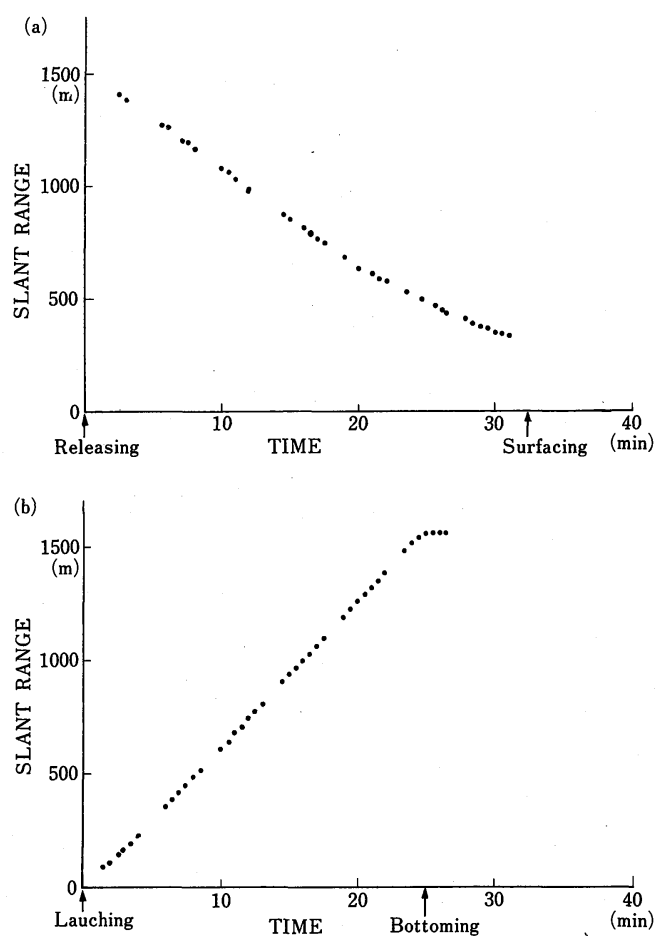

Fig. 10. Speed of the OBM while floating up (a) and falling down (b) were 'watched' by measuring the slant range from the ship to the OBM.

\section{Data Processing after Observation}

Although the verticality of the magnetometer is kept, the magnetometer is set on the ocean bottom in an arbitrary direction, and so $X$ and $Y$ components of the meter should be transformed for ordinary coordinates, such as geographical or geomagnetic north.

The sensor direction of OBM can be determined as follows with reference to the magnetic chart.

Firstly, absolute values of $X$ and $Y$ components of the magnetometer, $X^{\prime}$ and $Y^{\prime}$, are obtained from the observed data at midnight of geomagnetic quiet days, $\Delta X$ and $\Delta Y$, and the compensation values of the geomagnetic main field, $X_{\mathrm{c}}$ and $Y_{\mathrm{c}}$;

$$
\begin{aligned}
& X^{\prime}=X_{\mathrm{c}}+\Delta X, \\
& Y^{\prime}=Y_{\mathrm{c}}+\Delta Y .
\end{aligned}
$$

Secondly, geographically northward and eastward components of the magnetic 


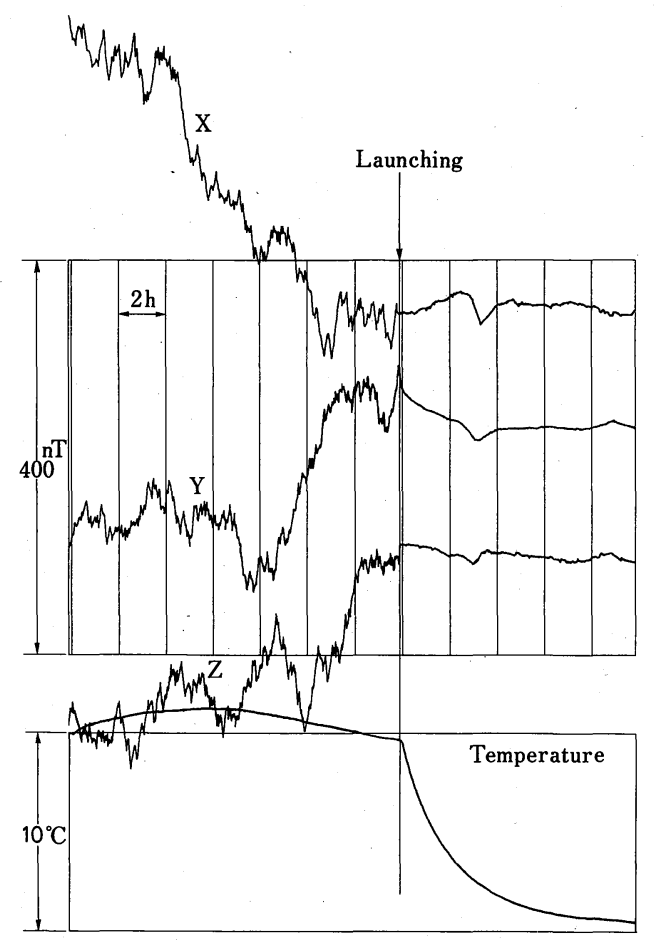

Fig. 11. Records of magnetic fields $(X, Y, Z)$ and temperature on board a ship and in the sea in launching the OBM.

field, $\bar{X}$ and $\bar{Y}$, can be calculated assuming deviation angle $A$ of the $X$ direction of the sensor from the geographically north.

$$
\left(\begin{array}{l}
\bar{X} \\
\bar{Y}
\end{array}\right)=\left(\begin{array}{lr}
\cos A & -\sin A \\
\sin A & \cos A
\end{array}\right)\left(\begin{array}{l}
X^{\prime} \\
Y^{\prime}
\end{array}\right)
$$

Suppose $X_{o}$ and $Y_{o}$ to be the geographically northward and eastward components of the geomagnetic field at the sea surface given from the magnetic chart, respectively. And then, the value of the angle $A$ is determined as ;

$$
\delta=\left(\bar{X}-X_{0}\right)^{2}+\left(\bar{Y}-Y_{0}\right)^{2} \rightarrow \min .
$$

The above-mentioned method is applied to the data obtained at Kakioka, described in section 4, in order to examine the reliability. As is seen in Fig. 13, transformed data, $\bar{X}$ and $\bar{Y}$, seem to be in good consistence with the KASMMER data, $X$ and $Y$, except for short period fluctuations where the periods are shorter than $20 \mathrm{~min}$. 


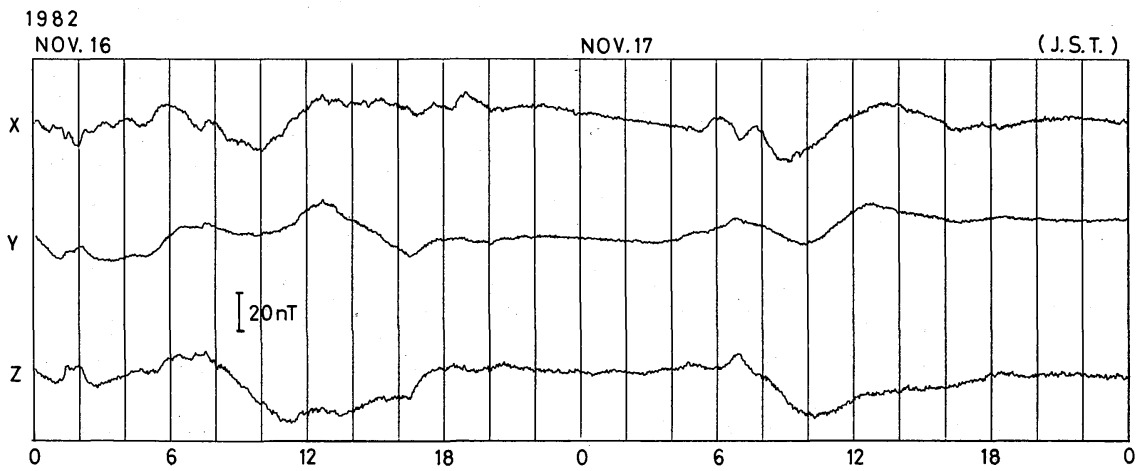

TEMPERATURE VARIATION

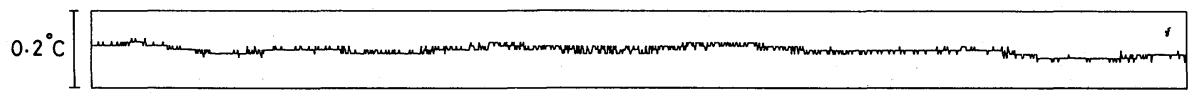

Fig. 12. Records of geomagnetic variations $(X, Y, Z)$ and temperature about 4 days after reaching the sea-floor. Many spikes seen on the temperature curve are regarded as fluctuations of least significance of $\mathrm{A} / \mathrm{D}$ converter, which corresponds to $0.01^{\circ} \mathrm{C}$.

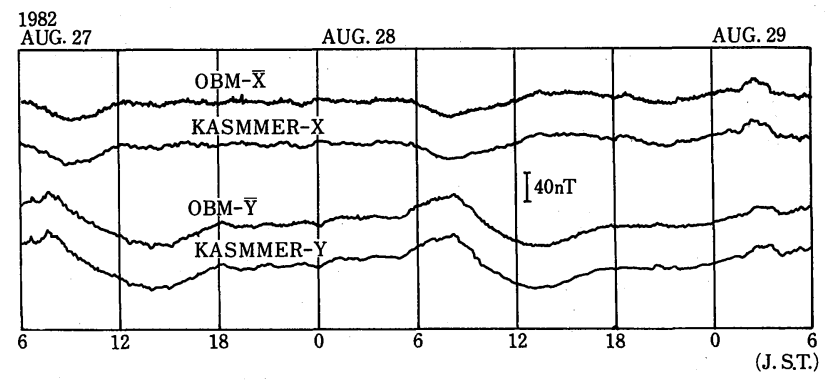

Fig. 13. Comparison of transformed horizontal components (OBM- $\bar{X}$ and OBM- $\bar{Y}$ ) of geomagnetic variation obtained in test at Kakioka with KASMMER's geographycal northward (KASMMER$X)$ and eastward (KASMMER-Y) components. Original data of OBM are shown in Fig. 12.

\section{Data Analysis}

\subsection{Methods}

It is known that anomalous geomagnetic variations of the vertical component for the short periods in the central part of Japan are related to the northward and eastward components as expressed below (RIKITAKE and YoKOYAMA, 
1955),

$$
\Delta Z=A \cdot \Delta X+B \cdot \Delta Y
$$

where $\Delta Z, \Delta X$, and $\Delta Y$ indicate the geomagnetic variations for downward, geographical northward and eastward components, respectively. $A$ and $B$ are complex functions of frequency or period and called transfer functions, which define a "preferred plane" that vectors of geomagnetic variations tend to lie on (Everett \& Hyndman, 1967). Period-dependent characteristics of these transfer functions are peculiar to the observation point and can be obtained by the spectral analysis for each component of geomagnetic variation. Transfer functions, $A$ and $B$, are written as follows by the method of EVERETT and HYNDMAN (1967);

$$
\begin{aligned}
& A=\frac{P_{z x} P_{y y}-P_{z y} P_{y x}}{P_{x x} P_{y y}-P_{x y} P_{y x}} \\
& B=\frac{P_{z y} P_{x x}-P_{z x} P_{x y}}{P_{x x} P_{y y}-P_{x y} P_{y x}}
\end{aligned}
$$

where $P_{x x}$ and $P_{y y}$ represent auto power spectra of $X$ and $Y$ components respectively, $P_{x y}, P_{z x}$ and the like are cross power spectra of $X$ and $Y, Z$ and $X$ and so on.

A preferred plane is expressed by projection of the normal vector of the plane onto a horizontal plane. Projected vector is called Parkinson vector, of which the magnitude is in proportion to the sine form of inclination of the plane and the orientation is a direction of the maximum inclination of the plane and points to the direction to which the higher conductive material exists. An expression of the Parkinson vector in terms of a real part (in-phase part) of transfer functions, $A u$ and $B u$, is given as follows by SCHMUCKER (1964),

$$
\begin{aligned}
& L=\sin \Theta, \quad \Theta=\tan ^{-1} \sqrt{A u^{2}+B u^{2}} \\
& \Phi=\tan ^{-1} \frac{B u}{A u}
\end{aligned}
$$

where $L$ indicates the magnitude of Parkinson vector, $\Theta$ the inclination and $\Phi$ the azimuth measured clockwise from geographical north.

Some anomalies of geomagnetic variations in the short period such as the central Japan anomaly can be discussed quantitatively and qualitatively by means of the above-mentioned transfer functions and Parkinson vector to some extent. The authors applied the method described in this section to the data obtained at the Sagami Trough and to the data of KASMMER for reference.

\subsection{Results}

Transfer functions take the complex values expressed as 

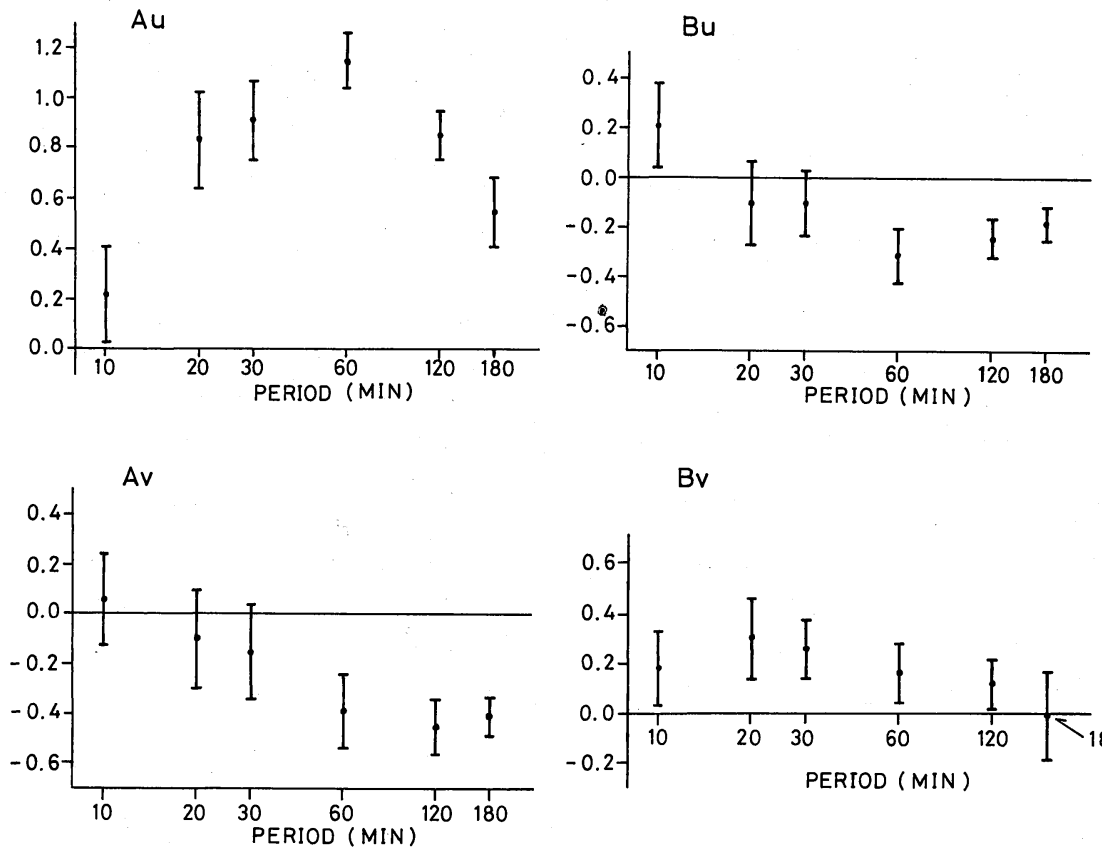

Bv

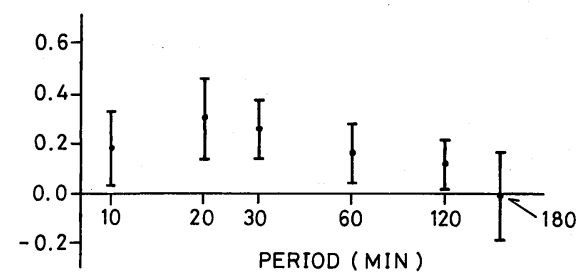

Fig. 14. Calculated transfer functions for period bands around 10, 20, 30, 60, 120, and 180 minutes from data of OBM. Suffixes $u$ and $v$ represent the real (in-phase) part and imaginary (out-ofphase) part, respectively. Error bars indicate the standard deviations.

$\mathrm{Au}$

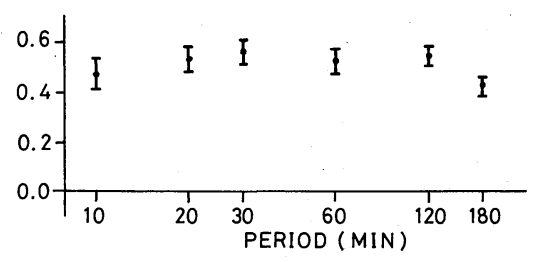

Av

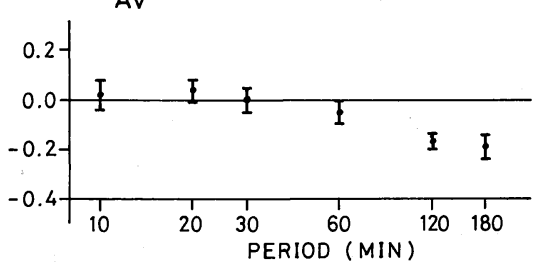

Bu
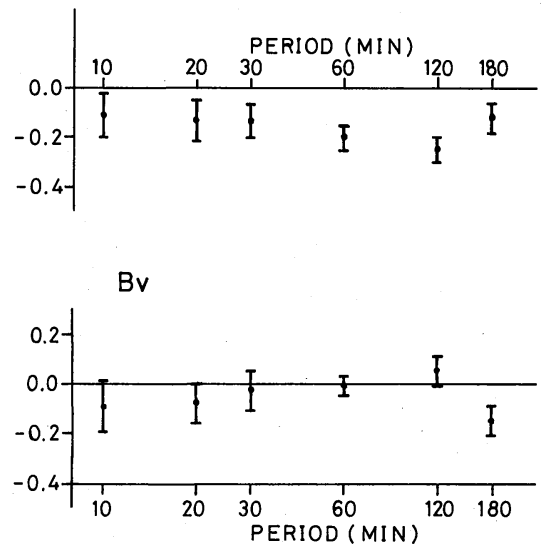

Fig. 15. Calculated transfer functions from the data of KASMMER. 


$$
\begin{aligned}
& A=A u+A v \cdot i \\
& B=B u+B v \cdot i
\end{aligned}
$$

$A u, A v, B u$, and $B v$ are determined for all components of Fourier transform and the mean values for period bands around $10,20,30,60,120$, and 180 minutes are obtained. These are shown in Fig. 14 and 15 with error bars which indicate standard deviations. Parkinson vectors for each period are shown in Fig. 16.

The transfer function $A u$ shown in Fig. 16 seems to have fairly large perioddependence and indicates typical central Japan anomaly which is characterized by large $\Delta Z$ in the case of the geomagnetic variation in the north-south direction for each period except for 10 minutes. Especially, for the period of 60 minutes, the value of $A u$ exceeds 1.0. While the value for the period of 10 minutes takes relatively smaller value, about 0.2 , independent of the direction of geomagnetic variation. This implies that geomagnetic variations for a period shorter than ten odd minutes could be affected by shielding of sea water or other kind of cause, e.g. effect of ocean current, or that another type of CA, i.e. high-cut $\Delta Z$ type CA, could exist.

Also concerning the Parkinson vector shown in Fig. 16, considerably large CA seems to exist.

\section{Discussion and Conclusions}

A new type of ocean bottom magnetometer, built on the basis of elementary work carried out over the last two years, was tested in various ways and fairly

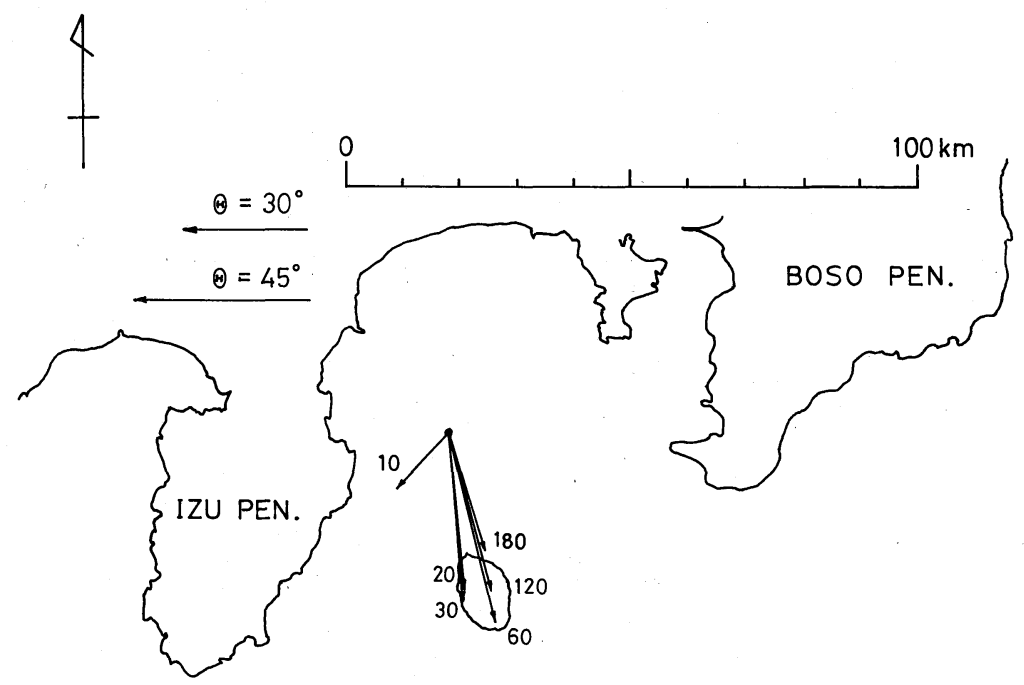

Fig. 16. Parkinson vectors for periods of $10,20,30,60,120$, and 180 minutes are indicated by arrows. Numerals by the arrows represent the periods in minutes. 
satisfactory results were obtained. However, it has not been clarified what causes the fluctuation for the short periods in comparison with KASMMER, which is seen in Fig. 8. This problem should be resolved in the future since the short period geomagnetic variation seems to be important for the induction studies.

It is necessary to interprete the results of data analysis taking into account the above-mentioned errors. For example, in the previous section, the peculiarities of the transfer function and Parkinson vector for the period of 10 minutes are described and it is difficult to judge whether the peculiarities are caused by the errors mentioned above, or not. But, standard deviation indicated as the error bar shows that a kind of anomaly is real as with other periods. It is desirable to examine what generates the shorter period anomaly by further investigations.

Anomaly of short period geomagnetic variation obtained by the analysis using transfer functions and Parkinson vectors seems to be in good agreement with the central Japan anomaly reported by HoNKURA (1974) and others.

A long-term observation is planned at the same site as the last two tests. For earthquake prediction using a time variation of the transfer function, as reported by HONKURA (1979), some new information may be brought to light from observations using the new type of ocean bottom magnetometer described in this paper.

The authors want to express thanks to Dr. M. Kawamura, the former director of Kakioka Geomagnetic Observatory, who allowed us to use their reliable data for comparison. The authors also thank Mr. Y. Iwasaki of the Department of Earth Sciences, Chiba University, who helped us in drafting. This work was supported by the Japanese Program on Earthquake Prediction - the 4th Phase 5-years Plan - from the Ministry of Education.

\section{REFERENCES}

EVERETT, J.E. and R.D. HYNDMAN, Geomagnetic variations and electrical conductivity structure in southwestern Australia, Phys. Earth Planet. Inter., 1, 24-34, 1967.

FillouX, J.H., An ocean bottom D component magnetometer, Geophysics, 32, 978-987, 1967.

FILloUX, J.H., Ocean floor magnetotelluric sounding over North Central Pacific, Nature, 269, 297-301, 1977.

FILlOUX, J.H., North Pacific magnetotelluric experiments, IAGA/IAMAP, General Scientific Assembly, Seattle, August-September, Working Group 1/3, paper G 271, 1977.

HONKURA, Y., Electrical conductivity anomalies beneath the Japan arc, J. Geomag. Geoelectr., 23, 147-171, 1974.

HONKURA, Y., Observations of short-period geomagnetic variations at Nakaizu (2): Changes in transfer functions associated with the Izu-Oshima-Kinkai Earthquake of 1978, Bull. Earthq. Res. Inst., 54, 477-490, 1979.

Kato, Y., M. Daguchi, M. Seto, and T. ARUgA, Northeastern Japan anomaly of upper mantle, Sci. Rep. Tohoku Univ., Ser. 5, 21, 19-35, 1971.

RIKITAKE, T., Anomaly of geomagnetic variations in Japan, Geophys. J., 2, 276-287, 1959.

RIKITAKE, T. and I. YOKOYAMA, The anomalous behaviour of geomagnetic variations of short period in Japan and its relation to the subterranean structure, The 6th report. (The results of further observations and some considerations concerning the influences of the sea on geomagnetic variations), Bull. Earthq. Res. Inst., Univ. Tokyo, 33, 297-331, 1955. 
RIKITAKE, T., I. YOKOYAMA, and Y. HISHIYAMA, A preliminary study on the anomalous behaviour of geomagnetic variations of short period in Japan and its relation to the subterranean structure, Bull. Earthq. Res. Inst., Univ. Tokyo, 30, 207-221, 1952.

SCHMUCKER, U., Anomalies of geomagnetic variations in the southwestern United States, J. Geomag. Geoelectr., 15, 193-221, 1964.

Segawa, J., T. KASUGA, and T. YUKUTAKe, Preliminary test on a three component ocean bottom magnetometer, J. Geod. Soc. Japan, 27, 239-251, 1981.

Segawa, J., T. Yukutake, Y. Hamano, T. KASUga, and H. UtAdA, Sea floor measurement of geomagnetic field using newly developed ocean bottom magnetometers, J. Geomag., Geoelectr., 34, 571-585, 1982.

TOMODA, Y., H. FUjimoto, Z. UChIYAMA, S. ONISHI, and Y. NAITo, Ocean bottom vector magnetometer - Trial device and its test-, J. Geod. Soc. Japan, 27, 131-139, 1981.

UChIYAMA, A., Y. TOMODA, Y. NAITO, and H. ToKiZAWA, Ocean bottom vector magnetometer (2) -Design and test of the bubble memory recording system-, J. Geod. Soc. Japan, 28, 22-28, 1982. 